\title{
Sharing the Korean Experiences for International Development
}

\author{
CHUN Seung-hun
}

President, The Korea Institute for Development Strategy

\section{CONTENTS}

I . Poverty and Development Cooperation

II. Korean Development and the Economic Dynamics of East Asia

47

III. Sharing of Development Experiences for More Effective MDGs

IV. Concluding Remarks

61

- References

65 


\section{Poverty and Development Cooperation}

\section{The Feature of International Development}

"Poverty reduction" is the core agenda of the global community, and is represented by the Millennium Development Goals (MDGs).

The global community has been making enormous efforts in the form of official development assistance (ODA). 'The MDGs are a firm determination of the global community to strengthen its efforts to assist, and to bring about significant reductions in poverty. As part of these efforts, the UN confirmed, in 2005, the target of ODA for 2015 as $0.7 \%$ of GNI. However, the performance of ODA so far has not been very satisfactory. No significant reduction of poverty in the global community has been witnessed. The UN estimated that over the last 25 years, the situation regarding poverty reduction has not gotten any better ${ }^{2}$. Through analysis, the World Bank noted that there was no observed correlation between ODA and economic development. ${ }^{3)}$

In this regard, we need to take a more indepth approach to ascertain the causes-of and remedies-for poverty. A time-series comparison of international poverty, 〈Figure 1) presents two maps of the world that show the level of per capita income for the years 1960 and 1999. From the maps, we can infer four facts regarding poverty in the world.

- Few countries have made significant improvements in poverty reduction during the past four decades.

- Relative progress in poverty reduction was witnessed in Asia, in particular, in East Asia.

- In Africa, in spite of enormous foreign financial assistance, the level of poverty remained relatively unchanged. ${ }^{4}$

- In South America, some countries are back on the track toward economic development.

From this observation, we can induce some

1) Donor countries provided USD 106.8 billion for ODA in 2005 , which is equivalent to $0.33 \%$ of GNI of DAC member countries

2) UN (2005), In Larger Freedom, p. 7.

3) World Bank (1998), Assessing Aid, pp. 121-125.

4) See footnote 12 for more details. 
implications for poverty reduction and economic development in the global community.

- Poverty reduction or economic development is not an easy task to overcome. Although most countries and people want to improve their standard of living, and the international community provides assistance, only a few countries or people have succeeded in considerable poverty reduction.

- ODA itself does not guarantee the poverty reduction of the recipients.

- Based on the dynamics of East Asia, development may be viewed as a learning or catch-up process. The existence of rapidly growing countries to benchmark provides a good learning environment for economic development.

Therefore, international poverty in developing countries is a chronic disease which is hardly cured. In this regard, we need to take a more careful approach for poverty reduction in the international community.

〈Figure 1〉 Changing Distribution of Per Capita GNP in the World [Year 1960]

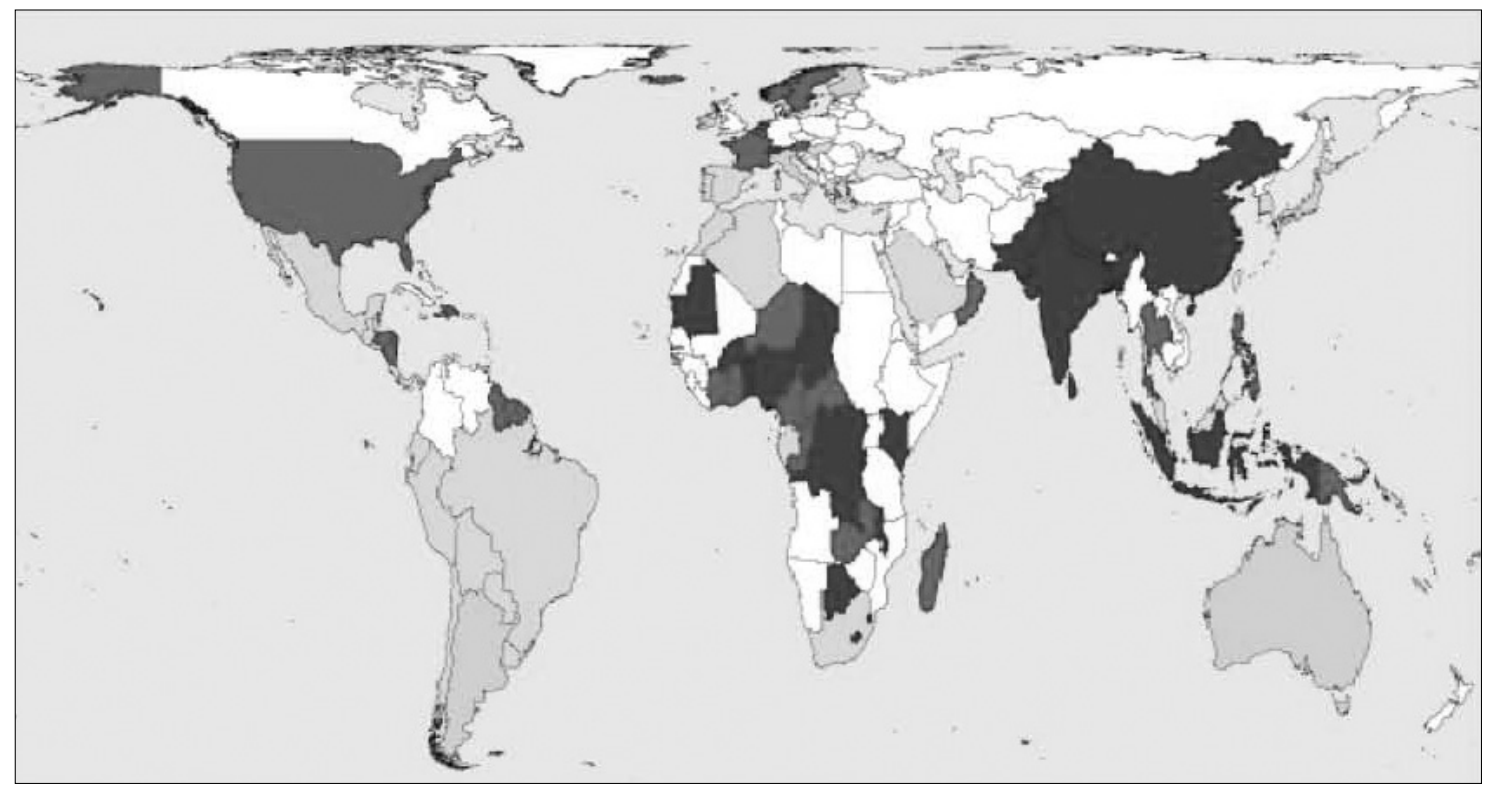




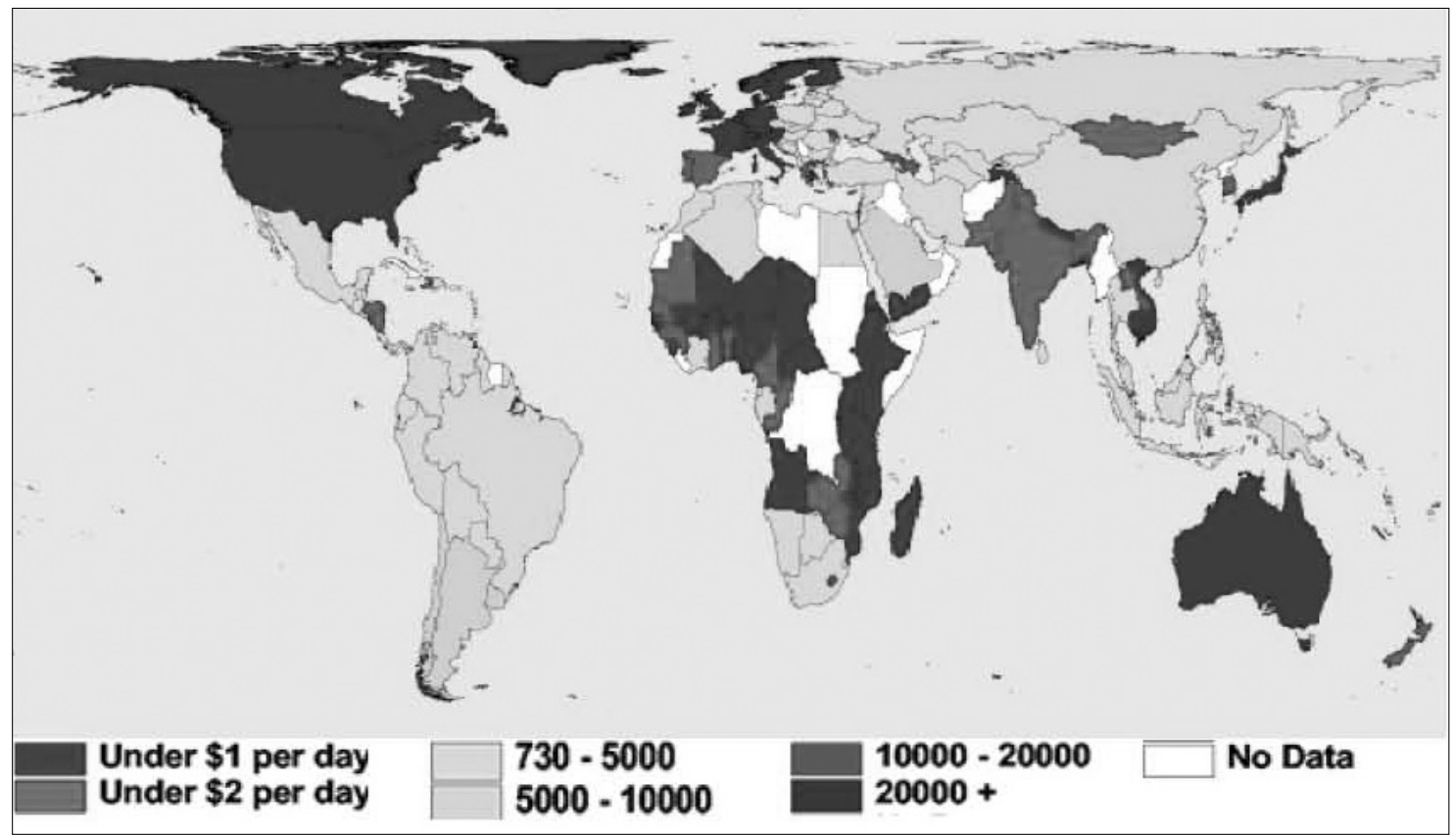

http://ucatlas.ucsc.edu/gnp/gnp.html

\section{Causes of Poverty and the Position of Developing Countries}

Why is poverty reduction that hard to attain? In searching for ways to reduce poverty, we need to examine the causes of poverty and categories: the circumstances in developing countries.

The causes of poverty in society are multidimensional, deep-rooted, and inter-related with each other. This is why efforts and external financial assistance are not as fruitful as expected. It may be reasonable to analyze the causes of poverty in four
- The consciousness of the people;

- Resource endowment;

- Governance failure; and

- International environment.

First, the consciousness and mindset of the people are considered the primary factors for economic development. Developing countries have endured historical elements such as colonial rule, socialism, and civil war. In particular, colonial rule may give the people a negative mindset or attitude, such as 
dishonesty, mutual disbelief, enervation and the lack of a self-reliant spirit. That the mentality or attitude of the people is hardly changed in a short period of time makes our efforts to reduce poverty much more difficult.

Second, although natural resources are surely a good means to improve the economy, many developing countries with abundant resources are poor. Sometimes abundance in natural resources calls for the intervention of powerful countries and results in exploitation and negates any opportunity to make use of the resources and pursue economic developing of their own.

Third, developing countries suffer from widespread corruption and lack of governance and development capacity. This causes the mismanagement of insufficient resources and discourages the willingness to work and inhibits the honesty of the people. However, it is very difficult for developing countries to build good institutions and governance systems. According to F. Fukuyama (2004), there exist two main obstacles on both the supply and demand side, which hinders the establishment of good institutions and governance. ${ }^{5)}$

Under these circumstances, external financial assistance itself may not always work. In a country with poor governance, any financial assistance from abroad may fail to reach to the target group, and may deteriorate the independent spirit and self-help efforts of the people.

Fourth, the international environment is not always helpful in developing countries. The key to poverty reduction and economic development is to accommodate sufficient enterprise, which creates employment opportunities and wealth. Free trade and the high mobility of capital and resources under globalization and the WTO system provide both threats and opportunities.

However, from the viewpoint of most developing countries, the opportunity is scarce, while the threat is enormous.

- For some countries which have accessibility to the global value chain, such as China

5). Refer to footnote 7. 
and India, globalization is a new opportunity.

- However, for many other countries which have no such advantages, it is very hard to foster local enterprise in a completely open market. The large-scale inflow of goods and services from abroad provides them with an environment under which the birth and growth of local firms are almost impossible.

- Mozambique, one of the poorest countries in the world, provides a good example of this. In an open market, a local start-up must contend with high financial costs which include 20\% interest, 17\% VAT, corporate taxes of $32 \%$, high labor costs, and low productivity. It is almost impossible to survive when there is an influx of much cheaper commodities from the rest of the world. ${ }^{6}$

An exploration of the circumstances in developing countries reveals to us that

developing countries are at very difficult positions with regard to poverty reduction and economic development. In particular, some developing countries are faced with a much more difficult situation under globalization.

\section{Some Mismatches between Needs of Developing Countries and the Provision of ODA}

Under these circumstances, external assistance might be an alternative solution. ODA certainly provides a well-intentioned means for countries to overcome poverty. The Marshall Plan is a good example. In Korea's case, if foreign assistance had not been provided, Korean's could not have maintained their living, or their economic prosperity. However, external aid has its limitations regarding the poverty reduction and economic development of the recipients.

First, in order for ODA to work as expected, it requires the good governance of the recipients. Poor governance leads to the misallocation of financial resources, and encourages corruption. This is why ownership and governance are stressed in international discussions regarding development

6) Song, Jang-June, Jae-Hoon Lee, and Seung-Hoon Chun (2006), National Strategy for the Development of Small-and Medium-Sized Enterprises in the Republic of Mozambique, The African Development Bank, pp.18-23. 
cooperation.

Second, it is very difficult for developing countries to build up good institutions for reasons which include both supply and demand: $:^{7}$

- On the supply side, the transferability of advanced institutions is low due to social and cultural difference.

- Without internal demand for good institutions, institutional reform is very difficult to implement. However, in developing countries, the demand for good institutions is rarely generated due to the pre-modern mindset of the people and of interest groups. ${ }^{8)}$

Unfortunately, a worsening combination of the above two factors are observed in ODA for some developing countries. According to F. Fukuyama (2004), "The international community is not simply limited to the amount of capacity it can build; it is actually complicit in the destruction of institutional capacity in many developing countries $\cdots$ Since independence, the ability of African governments to design and implement policies has deteriorated. In the words of the World Bank's African governors, 'Almost every African country has witnessed a systematic retrogression in capacity in the last thirty years; the majority had better capacity at independence than they now posses' (van de Walle, 2002). This deterioration in capacity has happened precisely during a period of accelerating external aid flows to the point where more than 10 percent of the GDP of the entire region comes from foreign assistance in various forms."

It seems very difficult for a country to overcome poverty and achieve economic development. Although ODA is very helpful, it is only external assistance. ODA might be necessary but it is not a sufficient condition for poverty reduction and economic development. Then, in searching for effective poverty reduction methods, it might be useful

\footnotetext{
7) Institutional capacity is composed of four factors: (1) organizational design and management; (2) institutional design; (3) basis of legitimization; and (4) social and cultural factors. Transferability of the former two factors is high or medium, while transferability of the latter is low or medium low. $\mathrm{F}$. Fukuyama (2004), State-Building, pp. 31-39.

8) The majority of cases of successful state-building and institutional reform have occurred with strong domestic demand for institutions rather than unilateral transfer of institutions from abroad. Early modern Europe; the United States after the American Revolution; Germany, Japan, and Turkey in the nineteenth century; South Korea and Taiwan in the 1960s; Chile; and New Zealand in the 1970s and 1980s were all such cases. If sufficient domestic demand exists, then supply usually follows, though the quality of that supply has varied from decade to decade..

9) F. Fukuyama (2004), ibid, pp. 39-40.
} 
to analyze how successful poverty reduction and economic development occurred in certain countries and regions.

\section{Korean Development and the Economic Dynamics of East Asia}

\section{Circumstances and the Development Performance of Korea}

As 〈Figure 1〉 shows, East Asia is the most dynamic region with regard to poverty, and Korea is positioned at the core. That is why the Korean experience draws attention from the international community.

Looking at the economic status of Korea, Korea remained among the poorest countries in the world until the early 1960s. To Western eyes, Korea was considered a hopeless country even compared with other Asian countries, such as the Philippines, Thailand, and Myanmar. However, during the last four decades, Korea transformed to become a modern industrial state.

- Having started modern economic growth from the above circumstance in the early 1960s, Korea achieved a remarkable performance. Its per capita GDP was raised from USD 79 in 1960 to USD 16,422 in 2005. Korea became a powerful manufacturing base for steel, automobiles, semi-conductors, ship-building, electronic goods, etc. This happened in a new republic with a population of only 40 million.

- In addition to economic development, Korea also succeeded in realizing democracy and freedom. In order to evaluate the usefulness of the Korean development experience, we need to examine differences in the initial conditions and resource endowment of Korea at the onset of modern economic growth in the early 1960s, and the circumstances of other developing countries.

First, with respect to the historical environment, Korea was a typical new republic born after World War II, and it experienced a very similar history to that of developing countries elsewhere. Korea had been under Japanese colonial rule for 36 years, until the country was liberated at the 
end of World War II.

- Immediately following independence, Korea endured partition which resulted in the three-year Korean War.

Second, with respect to resource endowment, many Western development economists attribute Korea's economic performance to highly educated people and an efficient bureaucracy. However, our analysis supports that no significantly favorable advantages were found in Korea over other developing countries.

- It is well known that Korea is endowed with poor natural resources, and is ranked as one of the worlds most densely populated nations.

- With a population growth rate of $3-4 \%$ and a fertility rate of $6-7 \%$, massive unemployment and food shortages were caused due to a lack of an industrial base.

- With respect to the population's mindset, it is likely that Koreans possessed the usual characteristics of other third world people, such as mutual disbelief, frustration, enervation and the lack of a self-reliant spirit.

- Educational attainment was also below the normal standard. Illiteracy among those aged over 13 was $28 \%$ and only half of the population had had elementary education.

With that in mind, Korea possessed no significant intrinsic advantages over contemporary developing countries. If other developing countries share similar initial conditions with Korea, there exist no significant reasons why contemporary developing countries cannot attain the economic developing that Korea did.

\section{Development Performance of Korea and} its Wavelength to the International Community

If there are no significant advantages for Korea over contemporary developing countries under the initial conditions and resource endowment, the achievements of Korean development may be attributed to the two following factors, which contemporary developing countries might not possess:

- Internally, political leadership and a feasible development strategy; and

- Externally, an environment to learn economic development. 
[Table 1] The Trend of GDP per capita for Several Selected Countries

Unit: USD

\begin{tabular}{cccccc}
\hline & $1970(\mathrm{~A})$ & $1990(\mathrm{~B})$ & $2005(\mathrm{C})$ & $\mathrm{C} / \mathrm{A}$ & $\mathrm{C} / \mathrm{B}$ \\
\hline Korea & 278 & 6,153 & 16,471 & 59.2 & 2.6 \\
China & 112 & 337 & 1,532 & 13.6 & 4.5 \\
Russia &. & 3,839 & 5,348 &.. & 1.3 \\
Vietnam & 64 & 97 & 630 & 9.8 & 6.4 \\
\hline Argentina & 990 & 4,338 & 4,730 & 4.7 & 1.1 \\
\hline Ghana & 246 & 402 & 470 & 1.9 & 1.1 \\
\hline
\end{tabular}

Source: UN (2006)

〈Figure 1〉 and [Table 1] in combination show that East Asia is a very dynamic region compared with other continents. [Table 1] shows that several countries in the East Asian region are changing more rapidly than some selected countries in other continents. Let us see the features of East Asia more closely.

Regionally, only Japan was an industrialized country, enjoying a high standard of living while most other countries remained underdeveloped until the early-1960s. Entering the early-1960s, Korea launched modern economic growth programs, and since then Korea has experienced enormous economic development. However, Korea is not the only country in the region which showed high economic growth. As 〈Figure 2〉 shows, Taiwan, Hong Kong, and Singapore belong in the same group with Korea, and were known as the Newly Industrializing Economies (NIEs).

High economic growth and effective poverty elimination in Korea and the other first-tier 〈Figure 2〉 Dynamics in East Asia

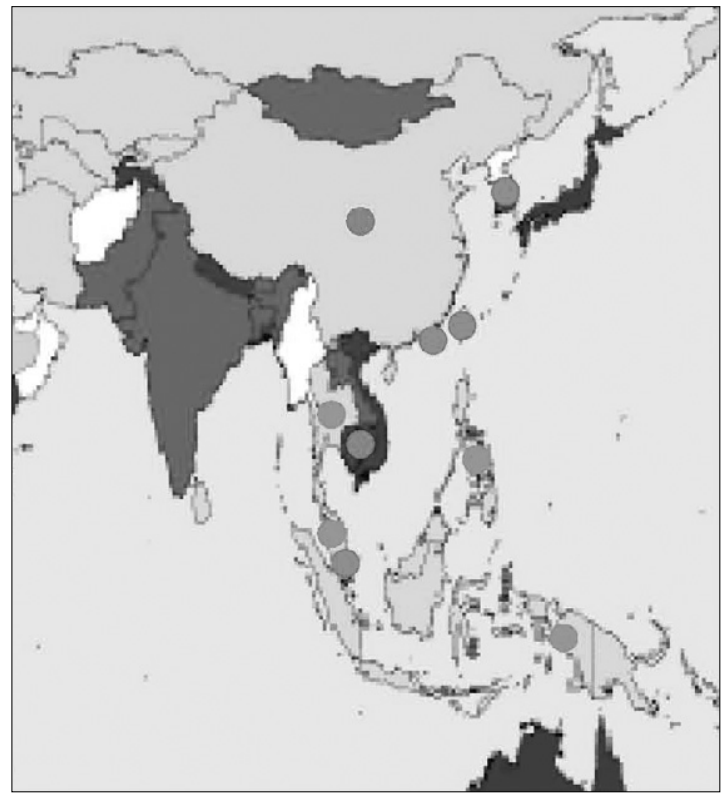

First-tier NIEs: Korea, Singapore, Hong Kong, Taiwan Second-tier NIEs: Malaysia, Indonesia, Thailand, Philippines Third-tier NIEs: China, Vietnam

Source: http://ucatlas, ucsc edu/gnp/gnp htm 
economies mentioned above created a the political situation in the region.

wavelength in the region, as was represented in $\langle$ Figure 2〉. As the first tier economies started to run, neighboring nations were also motivated and ready to follow them. Following the first-tier economies were Malaysia, Indonesia, Thailand, and the Philippines. The wavelength then spread, in succession, to the rest of the region. This saw the rise of the third-tier which included both China and Vietnam. The economic dynamics in East Asia seemed to be largely motivated by diffusion and the demand to learn development experiences, which also changed

- The first formal reaction to the success of Korea came from the then-Prime Minister of Malaysia, Mr. Mahatir, who declared his "Look East Policy” in 1981.

- Breaking through a long diplomatic silence, Russia opened diplomatic relations with Korea in 1990, and China in 1992 which resulted in strengthened economic exchanges with Korea as shown in $\langle$ Figure 3$\rangle$.

- China was particularly keen to learn from Korea's experiences. For instance, China

〈Figure 3〉 GDP Trends per capita for Several Selected Countries

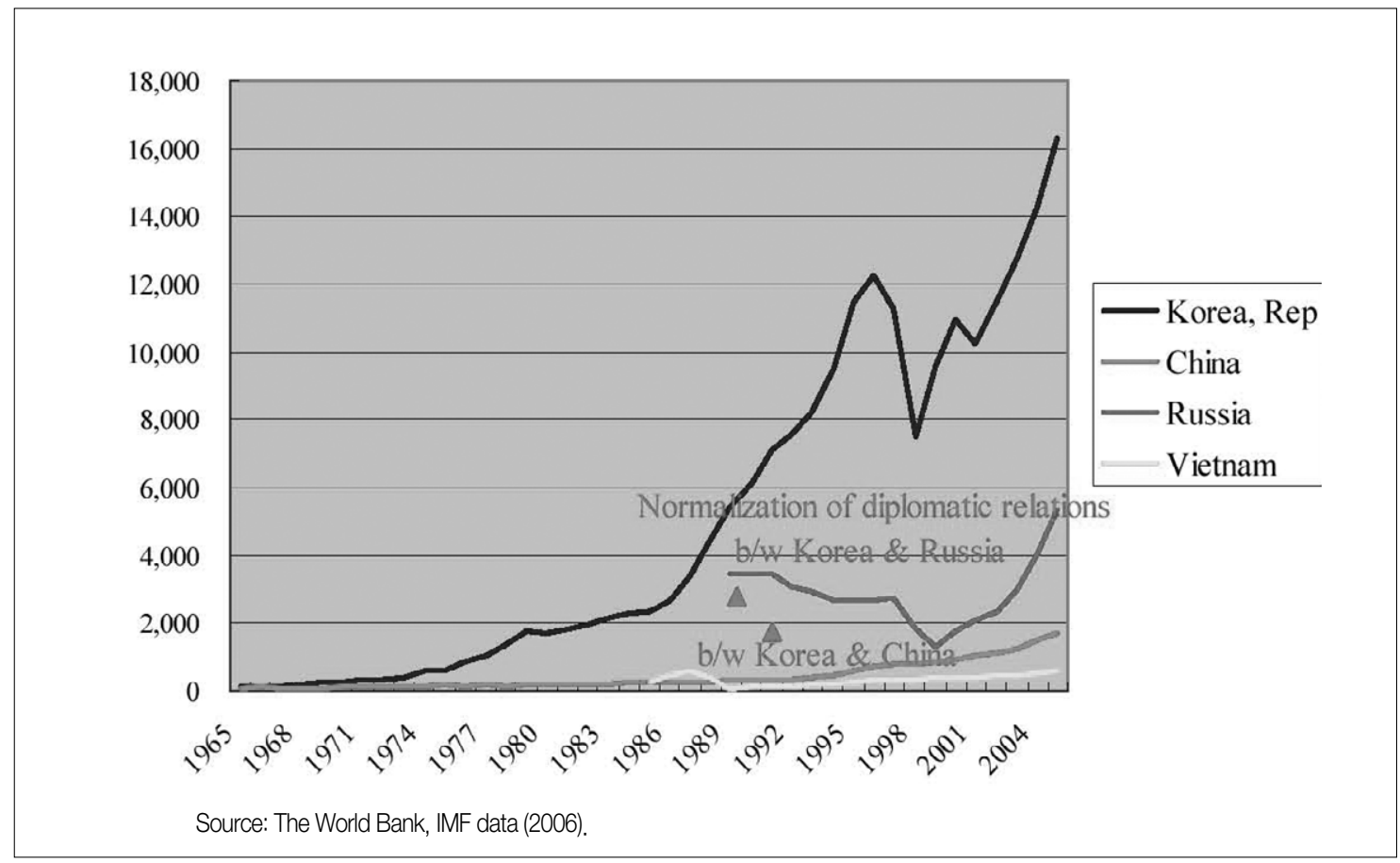


officially introduced the Korean vocational training system in 1997, and the ruling Communist Party moved to benchmark the Saemaul Undong of Korea in launching the New Countryside Movement in 2006.

- Many other countries, including Vietnam, Mongolia, and Cambodia, took similar steps to benchmark the Korean experience.

\section{Some Lessons from the Dynamics of East Asia}

What factors are attributable to the economic dynamics in East Asia? On the assumption that there exist no significant internal advantages for the countries in the region over those in other continents, except for factors which include, internal leadership, feasible strategies, and external learning environments, as was presented in the previous section.

From the economic dynamics of Korea and East Asia, we may infer that internal factors such as political leadership and feasible strategies may not be the dominant variables for poverty reduction. Thus, the external learning environment should also be considered.

- That economic development was not limited to a specific country but happened as a chain reaction which implies the importance of environmental factors.

- The internal factors of political leadership and feasible strategies might also be influenced by the learning environment.

- Koreans were provided with motivation and opportunities to learn from neighboring Japan, which already belonged to the advanced country group at that time. In particular, from the historical notion that Korea was ahead of Japan in civilization, the Koreans possessed a latent consciousness that the Koreans could do what the Japanese did. ${ }^{10)}$

- The economic history of the world also supports that economic development is a learning or catch-up process. "The industrialization of Western Europe and America, to a large extent, is a study of

10). Until the 7th century, building a state and culture of the Ancient Japan was led by the Koreans, and historically the continent culture was transferred to Japan through the Korean peninsular by the Koreans. Han, Yung-u (1997), The History of Korea, pp. 120-124. Also Garraty, John A. \& Peter Gay (1981), The Columbia History of the World, pp. 335-337. 
diffusion. In the spread of Industrial Revolution, the process of diffusion began with the realization by other nations that the British had certain industrial processes which gave them price and style advantages. Industry and technology are in advance diffused to areas which were in close communication with England, where economic conditions were very similar to those in which the breakthroughs of new methods of production had been made."

- It is for this reason that G8 Gleneagles (2005) notes that South-South cooperation can make a significant contribution, and that the UN continuously supports SouthSouth cooperation through its development programs.

The economic dynamics of Korea and East Asia suggest some lessons for effective strategies regarding poverty reduction and the MDGs in the global community.

- Creating a regional learning environment, which motivates the people and governments concerned, is very useful for poverty reduction.

- More specifically, the latest development experiences from similar circumstances may be more effective in providing motivation and knowledge for developing countries.

In this respect, a more harmonized role between emerging donors and advanced donors is desirable for effective international poverty reduction. Emerging donors with the latest development experiences are in a good position to make up for the room left by the advanced donors, although their amount of assistance is very meager compared with that of advanced donors. In this regard, sharing knowledge and experience may be considered the most important factor for poverty reduction and economic development as elementary school students, senior students, and elementary school teachers might be better than university professors.

11). Garraty, John A. \& Peter Gay (1981), ibid, p. 835. 


\section{Sharing of Development Experiences for More Effective MDGs}

\section{The Usefulness of the Korean Development Experience, Reconsidered}

Having learned the importance of sharing development experiences for international poverty reduction, we need to analyze the supply and demand conditions for practical application. The experiences of Korea may also provide a good model, in that Korea is positioned at the core of East Asian dynamics.

Among the attributes of development experiences, the Korean ones are particularly meaningful and useful for contemporary developing countries in following three ways:

- The experiences were formed in similar historical and socio-political circumstances, which differentiate from those of Western advanced countries.

- The experiences are more recent, which provides contrast with those of Western European countries and Japan.

- The experiences were obtained in a normal state, which differs from those in citystates such as Hong Kong and Singapore.

Korean experiences are especially useful for international poverty reduction, in that they were formed under similar circumstances to contemporary developing countries. Areas which can be taken from the Korean experience cover the following vital tasks that contemporary developing countries must face while on their way toward poverty reduction and economic development:

- (HRD) At the beginning of modern economic growth, the prevailing attitudes of most Korean workers were pre-modern, and skills were severely lacking. Therefore, the Korean government placed great emphasis on human resources development (HRD), and gained great success. This is evident, in that Korea achieved remarkable development performance, and that human resources were the only resources which Korea was able to rely on. Korea agricultural workers, for example, were transformed swiftly into modern industrial laborers through the initiation and strong training programs of the government.

- (Governance) As a newly born country 
after World War II, Korea had to build its own institutions and governance systems. Poor governance is accepted as one of the main factors which hinder poverty reduction. However, governance is hardly improved by external assistance, though Korea is quoted as a successful case. ${ }^{12)}$ In this regard, Korea's experience is particularly useful for developing countries while they make efforts to improve governance.

- (Rural Development) Pre-modern characteristics of rural regions in developing countries represent backwardness and underdevelopment, which hardly changes over time. However, in Korea, the rural sector was completely modernized through a grand rural development movement called the Saemaul Undong. This unique experience of successful rural development became a model to many developing countries, such as China, Cambodia, the Philippines, Mongolia, and the Congo.

- (Industry and Enterprise) As is the case in many developing countries, Korea was also considered as an infertile land for enterprise. However, Korea had succeeded in fostering world class enterprise such as Samsung, LG, and in developing competitive small and medium enterprise (SMEs) at the grass-roots level. Since the success of poverty reduction and economic development depends on whether a country can experience the sufficient growth of enterprise, the Korean experience in this field may be useful for international poverty reduction.

- (IT) In a short period of time, Korea emerged as one of the strongest countries for internet and IT technologies. In this era of information and knowledge, IT should be an opportunity for developing countries.

- (Some failure) Although development policies with strong government initiatives turned out to be effective, they were also accompanied by some serious side effects, as was represented by the financial crisis of Korea in 1997. Both Korean failures and successes should provide a good lesson for developing countries. From failures, Korea learned a good lessen that timely incorporation of the global standard into the economy is very important for sound

12) F. Fukuyama (2004), ibid, p.39. 
and stable economic development.

Advantages of the Korean experience are not the whole story. The Korean experience also contains some limitations when applied to contemporary developing countries.

- (International Environment) There exist significant differences in the international environment between the 1960s and the 2000s to be faced by contemporary developing countries. Under the WTO system, the latter period becomes much more globalized, and industrial policy to protect local industry and business firms is no longer applicable. The means of developing country governments for industrial development is very limited, compared with that of Korea in the past.

- (The level of Industrial and Economic Development) There exists a great variety in the level of industrial and economic development among developing countries. For instance, some African countries are still at their infant stage of agriculture, while some Asian countries already have a considerable basis of IT and high technology industries. We need to apply development experiences to fit the specific needs of partners.

- (Culture and Social Customs) Cultural, religious, and racial differences often cause difficulties in transferring knowledge and experiences to a specific country.

\section{The Poverty Front in the Global Community}

For effective strategies for poverty reduction and the MDGs, we need to analyze the situation of poor regions around the world. After the analysis, we need to provide them with the appropriate knowledge and assistance.

The poverty front in the global community is formed throughout Asia, Africa, Central and South America. The situation of poverty for each poverty front may not be the same.

The differences in the historical development of civilization, geographical location, religion, culture, and politics result in different causes of poverty. Let us explore the major poverty front in the global community, i.e., Asia, Africa and Latin America.

Asia: In this region, some significant 
movement has already occurred in many countries as was presented in the previous section. 〈Figure 2〉 tells us that this happened in the first-, second-, and third-tier economies. Among the nations that did not develop, lack of governance may explain the cold response to the wavelength of economic growth. The continuous spread and diffusion of knowledge and technology from the growing neighboring countries are expected to bring more positive responses from those countries. HRD, governance, and rural development are high priority tasks for poverty reduction. For transition economies in Central Asia, the soft-landing of market economies has also become a key task for economic development.

Africa: The most serious and main poverty front in the world is sub-Saharan Africa. As 〈Figure 1〉 shows, no significant progress toward poverty reduction has occurred. It is quite disappointing, in that it is where donors have provided the largest portion of ODA. ${ }^{13)}$ The region attracts attention by the global aid community, and many assistance programs are funneled into this region. Various factors to explain poverty such as poor HRD, mal-nutrition, and weak governance, are deep-rooted and interrelated with each other, which incapacitates most assistance efforts by global community.

This region presents all the factors of poverty, and the international aid community tackles each factor of poverty on their own. However, the performance of the assistance is not satisfactory. More fundamentally, it seems that the region has not taken the normal development stages of human civilization. ${ }^{14)}$ The region has not completely overcome stages of human settlement and agriculture yet. Most factors of poverty, such as weak governance and low productivity, are related to this fact. Under these circumstances, more concentrated efforts for rural development and resource-based industrial development seem much more effective for poverty reduction than tackling every factor at once. Although reducing the period of any stage of social development may be feasible, complete omission of any seems

13) According to UN 2003 statistics, USD 22.7 billion, $32 \%$ of the world ODA, equivalent to 18.6\% of the total GDP, was provided for sub-Saharan African countries.

14) Human civilization has undergone three great waves, namely agriculture, industry, and knowledge/information. Alvin Toffler (1980), pp. 10-11. 
not possible for the smooth development of a society.

Central and South America : The countries in this region have very advanced partners in their neighborhood. In particular, some countries in the region are making no significant progress under globalization. Under a completely open market, multinational firms are given much easier access to global procurement, rather than to local procurement. This causes a break down of the basis for the development of local SMEs. It seems that the core of poverty reduction seems to be in whether they can provide a sound basis for the growth of SMEs. The improvement of the business environment and upgrading entrepreneurial skills may be considered as key factors for the poverty reduction strategy in the region.

\section{Demand for Learning Development Experiences}

Reflecting on the situation of poverty in the world, the demand for development experience is great. First of all, strong demand for development experience was created in East Asia when the first-tier economies including Korea started to run. This wavelength spread to the second-tier group, and then to the third-tier, as was discussed in section "II-2." The fields of interests cover HRD, governance, fostering SMEs, and capacity building. However, the most popular fields are vocational training, Saemaul Undong for rural development, IT, and capacity building for development. ${ }^{15)}$

The demand for learning development experiences is not limited to Asia, and it begins to extend to other continents, such as Eastern Europe, Africa, and Latin America. Due to the development of IT and globalization, physical distances no longer provide barriers to the flow of information.

- The CIS countries expressed particular interest in experiences which would help their new market economies soft-landings.

- African leaders expressed their hope for Korea to participate in transferring development experiences and to strengthen economic ties with Korea at the $1^{\text {st }}$ Korea-

15) For details, refer to section "III-1." 
Africa Forum in 2006.

- Central and South American countries wanted Korea to contribute to vocational training systems and to help with the development of SMEs.

\section{A Comprehensive Approach toward More Effective MDGs}

\section{Strategic Approach toward International Poverty Reduction}

If poverty reduction and thus the attainment of the MDGs are the core task of the global community, we need to take a more strategic approach to achieve the objectives. From the analysis of global features of poverty and economic development, particularly for the successful performance in East Asia, we may draw some implications for poverty reduction strategies in the global community.

- Creating a learning environment for development, as in East Asia, would be a very effective strategy for international poverty reduction.

- The effective diffusion of the latest development experiences formed under similar circumstances to developing countries is very useful for poverty reduction.

- Concentration of our assistance to the specific needs of each poverty front is necessary for effective ODA. For instance, in sub-Saharan Africa, rural development and agriculture- or resource-based industrial development could be core aspects for their poverty reduction strategies. In Central and South America, the improvement of business environments and the upgrading of entrepreneurial skills for the development of SMEs might benefit their poverty reduction strategies for the region.

- Development of best practices for poverty reduction and economic development from the latest development experiences is helpful for developing countries for their efforts to reduce poverty. For instance, Korea's rural development program and vocational training system are popular and the demand is high.

In order to put into practice the above implications, partnerships between advanced donors including international aid institutions, and emerging donors with the latest development experiences needs to be 
encouraged.

\section{The Responsibility and Role of Korea}

Having played a key role in the dynamics of East Asia, Korea has to take more responsibility in sharing development experiences with the global community.

- Korea was indebted due to its subsistence and economic prosperity from the assistance and support of the international community. Now is the time for Korea to extend compensation for the assistance it had received from the international community.

- Korea possesses a unique and recent development experience and knowledge for poverty reduction, and the demand for them from developing countries is great.

- As a member of the OECD and the 12th largest economy in the world, Korea needs to increase its role as a responsible member of the global community.

However, until recently, Korea seemed hesitant to fully embrace its responsibility.
Perhaps the history of Korea's development was too short for Koreans to become fully aware of their changed position in the world. Nevertheless, Koreans are becoming well aware that taking full responsibility as a member of the global community is not only humanitarian justice, but also beneficial to one' s sustained development.

In order for Korea to bear full responsibility in the global society, its ODA policies need to be geared in the following interrelated directions:

- (ODA Volume) Although Korea recently increased the volume of its ODA, the gap between Korea and the OECD average is still quite large. ${ }^{16)}$ The lower volume of Korea's ODA may be partly due to assistance toward North Korea, and to the relatively low level of per capita income. Nevertheless, in order to meet the expectations of the global community, Korea needs to strengthen its efforts to reduce the gap in the near future.

- (Development of Aid Content) As a country possessing the latest development

16) The portion of ODA in per capita GNI of Korea is $0.1 \%$ in 2005 , while that of OECD average is $0.33 \%$. 
experiences, Korea is required to develop content based on its development experiences. For instance, in spite of great demand to learn of Korea's rural development, no good references are available yet.

- (Fostering Aid Industry) The effective sharing of Korea's development experience requires a sound basis for development consultancy. Due to the weakness of private consulting, the development experiences of Korea are not yet readily available or delivered to end-users in the developing world.

- (Aid Alignment and Harmonization) The ODA of Korea is implemented largely by project-based approaches and with many fragmented projects for large numbers of countries. This lack of feasible country programming causes inefficiency in ODA and in transferring development experiences. Recently, the Korean government took significant steps toward enhancing the alignment and harmonization of aid.
International Support for the Effective Sharing of Development Experiences

Although some countries with successful development experiences possess good content for international poverty reduction, their contribution might be limited for the following reasons:

- Since those countries are still on the way to economic development, their financial capacity for ODA is limited compared with those of advanced donors.

- They are still weak in their capacity to develop poverty reduction content.

- Their aid capacity and technology are not fully established.

- Their aid industry is still in its infancy stage to deliver effectively their experiences to developing countries in need.

With this in mind, it is required for international aid institutions and advanced donors to strengthen their partnerships with the countries who possess the latest development experiences.

- In consideration of financial and aid 
capacity constraints of the latter group, the former party of international institutions and advanced donors needs to help the latter countries in their efforts to share development experiences.

- International aid agencies need to enlarge doors to procurement of consulting services for consulting firms of the latter country group.

- Establishment of international institutions such as a regional poverty reduction center in those countries which demonstrates sound economic development and the latest development experiences might be useful for effective transfer of development experiences.

- International institutions need to encourage close partnerships between advanced donors and the latter countries in implementing ODA programs.

\section{Concluding Remarks}

"Poverty reduction" is the core agenda of the global community, as is represented by the Millennium Development Goals (MDGs). However, developing countries are in very difficult circumstances for overcoming poverty. The mindset of the people is negative. Local resources do not guarantee their economic stability without possessing power to keep them. Usually governance is poor, and introducing advanced institutions do not work properly. In particular, under globalization, most developing countries cannot foster enterprises due to the massive inflow of cheap products in the global market except for countries which have the advantage of being able to access the global value chain. It seems that international poverty is a chronic disease which can not easily be cured.

An overview of international poverty also supports that international poverty reduction is rarely attained, and only East Asia shows enlarged progress in poverty reduction and economic development. The economic dynamics in East Asia may provide useful implications for international poverty reduction strategies.

Effective poverty reduction in East Asia occurred as a ripple effect, created by Korea and the first-tier economies including Taiwan, and Singapore, to the neighboring countries of Thailand, China, Vietnam, etc. 
The growth of neighboring countries provides an environment of motivation for and diffusion of knowledge. From the economic dynamics in East Asia, we may infer that learning environments and diffusion of development experiences are very effective for international poverty reduction. The economic history of the world also supports that economic development is a learning or catchup process.

With regard to development experiences, the Korean experience may be particularly useful, in that they are the latest example from a normal state with similar historical and socio-political circumstance. The Korean experience contains especially useful content for poverty reduction, covering the most important tasks faced by other developing countries on their way to poverty reduction and economic development, such as HRD, governance, rural development, development of industry and enterprise, IT and some failures represented by the 1997 financial crisis. However, the Korean experiences also contain some limitations due to differences in the international environment, as well as some other factors.
For the diffusion and sharing of development experiences, we need to analyze the demand for development experiences at the poverty fronts, and provide efficiently appropriate knowledge and assistance.

Asia: In this region, some significant movement has already occurred from the first-tier economies including Korea to the second-tier and third-tier countries of China and Vietnam. In this region, HRD, governance, and rural development are considered as main tasks for poverty reduction. For transition economies in Central Asia, the softlanding of their market economies also becomes a key task for economic development.

Africa: Sub-Saharan Africa is considered the most serious poverty front in the world. The region has not completely undergone fully, the stages of human settlement and agricultural revolution yet. In this regard, concentrated efforts for rural development and agriculture- and resource-based industrial development seem vital for effective poverty reduction. 
Central and South America: Instruction on how to develop SMEs under globalization is a key task. Improvements in the business environment and the upgrade of entrepreneurial skills aiming to foster SMEs are a useful means for poverty reduction and economic development.

The demands for the most recent development experiences from the above poverty fronts are great. Firstly, in East Asia, strong demand for development experiences was created, and this helped realize effective poverty reduction and economic development in the region. Later, the demand extended to other continents, such as Eastern Europe, Africa, and Latin America.

Effective diffusion of development experiences requires increasingly harmonized efforts between advanced donors including international aid institutions, and emerging donors with the latest development experiences..

With regard to countries with the latest experiences, they need to gear their ODA policies in the following directions.
- First of all, they need to strengthen their efforts to increase their ODA volume.

- They are also required to develop contents for poverty reduction based on their latest development experiences.

- It is necessary to foster development a cooperation consultancy industry for the effective delivery of development experiences.

- ODA policies need to be pursued under the principle of international "Alignment and Harmonization."

In consideration of the financial and aidcapacity constraints of the latter countries, international institutions and advanced donors needs to strengthen their partnerships with the latter countries for the effective diffusion of development experiences.

- International institutions and advanced donors need to help the latter countries in their efforts to share development experiences.

- International aid agencies need to enlarge doors to procurement of consultancy services for consulting firms of the latter countries.

- Establishment of international institutions 
such as a "regional poverty reduction center" may be useful for the effective transfer of development experiences.

- International institutions need to encourage close partnerships between the former advanced donors and the latter countries in implementing their ODA programs. 


\section{[ References ]}

Chun, Seung-Hun et al. (2006), Mid to Long-term Bilateral Aid Policy of Korea (in Korean), Korea International Cooperation Agency

Fukuyama, Francis (2004), State-Building. Governance and World Order in the $2^{1 \text { st }}$ Century, Cornell University Press

Garraty, John A. and Peter Gay (1981), The Columbia History of the World, Harper \& Row Han, Yung-u (1998), The History of Korea, Saekyungwon

O, Won-Chul (2003), Korean Model of Economic Construction, Series 1-7 (in Korean), Korea Type Economic Policy Institute

Roeskau, Michael (2006), "Development Co-operation: Korea's New Role in the $21^{\text {tst }}$ Century" in International Development Cooperation, pp. 125-136, Korea International Cooperation Agency

Sachs, Jeffrey (2005), The End of Poverty, The Penguin Books

Song, Jang-June, Lee, Jae-Hoon, and Chun, Seung-Hun (2006), National Strategy for the

Development of Small-and Medium-Sized Enterprises in the Republic of Mozambique, The African Development Bank

Stiglitz, Joseph E. (2002), Globalization and Its Discontents, The Penguin Books The World Bank (1998), Assessing Aid. What Works, What Doesn't, and Why

The World Bank (2003), Better Governance for Development in the Middle East and North Africa. Enhancing Inclusiveness and Accountability

Toffler, Alvin (1980), The Third Wave, A Bantam Book

UN (2005), In Larger Freedom, 2005

Van De Walle, Nicolas (2001), African Economies and the Politics of Permanent Crisis, Cambridge University Press 